\title{
SUPER-GENES AND MIMICRY
}

\author{
C. A. CLARKE and P. M. SHEPPARD \\ Departments of Medicine and Zoology, University of Liverpool
}

Received 23.v.59

\section{INTRODUCTION}

Iт has been shown (Clarke and Sheppard, I96oa) that only two loci control the main differences between the various mimetic and nonmimetic forms of the female of the African butterfly Papilio dardanus. As far as colour and pattern are concerned only one locus apparently is responsible, the presence or absence of "tails" on the hindwing being determined by the other. This mode of genetic determination does not necessitate that each pattern arose fully perfected as the result of a single mutation, but only that the various allelomorphs act as a "switch mechanism", the actual patterns thus switched having evolved gradually as the result of the accumulation of modifiers (see Ford, I953; Clarke and Sheppard, I96ob). Moreover, as we will attempt to show in this paper, it is probable that the switch mechanism itself evolved by a series of small steps and what now appears to be a single locus is really a super-gene.

\section{THE PRIMITIVE PATTERN}

It is impossible to determine with certainty the primitive colourpattern of $P$. dardanus (that present just before the first mimic evolved) since this is a matter of pre-history. However, it is possible to make an enlightened guess on the matter. The males of this species are everywhere the same in general pattern although the details vary slightly from race to race. They all have tailed hindwings and a black and yellow pattern, the yellow pigment fluorescing under ultra-violet light. Even the very distinct subspecies or species humbloti from Grand Comoro has this type of male although the shape of its wings, the exact distribution of black pigment and the length of the tails are somewhat different. The males of this form also differ from those of the eastern races of dardanus in the structure of their genitalia which are like those of the western race. We must therefore either conclude that all the various males have (i) previously diverged and then converged with respect to pattern, (ii) evolved in parallel with one another, or (iii) remained fairly constant, the present pattern being that of the common ancestor of all the races. The third view seems the most likely for several reasons.

I. Yellow fluorescent pigment and the presence of tails are characteristic of a large proportion of the members of the genus Papilio suggesting that these were possessed by a common ancestor. 
2. Papilio nobilis, a distinct species (with several subspecies) from East Africa, considered to be closely related to $P$. dardanus but having a different ecology particularly in the immature stages, also has tails and the same general colour-pattern as $P$. dardanus but with the black areas replaced by brown. Since this species is closely related to $P$. dardanus but ecologically distinct it seems more likely that the common colour-pattern is due to the retention of a common ancestral form rather than to convergence.

3. In other butterflies in which the females are polymorphic or mimetic but the males monomorphic and non-mimetic the latter usually resemble closely related species. Since there are many such examples (Speyeria diana, Argynnis paphia, Papilio glaucus, P. cynorta, $P$. echerioides, Hypolimnas misippus and $H$. bolina to mention only a few), it seems unlikely that all can be due to convergence. It is more probable that the close resemblance between the males of related species reflects the conservation of an ancestral pattern. The reason for the relative constancy of male pattern may reside in the nature of butterfly courtship. It is known that colour is important in butterfly mating behaviour and Ford (1953) has suggested that this is particularly true in the male and that a novel colour-pattern fails to stimulate the female to copulate. Consequently male colour-pattern is particularly conservative, as demonstrated by the rarity of polymorphism in male butterflies as compared with females.

For the reasons given, it scems likely that the male colour-pattern is older than the races of $P$. dardanus. This does not tell us whether the females also had this pattern since it is possible that the species had become sexually dimorphic before the mimicry had been evolved. In those populations of $P$. dardanus where the mimicry is absent (Grand Comoro, humbloti, and Madagascar, meriones), there is no marked sexual dimorphism, the females being tailed and having the yellow and black pigments of the male. In the only other race which is well isolated (antinorii), all the females have tails and those with a malelike pattern are the commonest form, constituting some 80 per cent. of the female population. There is some gene exchange bctween all the other continental races, at the present time, and none has females possessing tails or the male-like pattern. One, polytrophus from Kenya, does possess, however, a small proportion of insects which have varying amounts of fluorescent yellow pigment (see below).

That the two races without mimics are not sexually dimorphic suggests that the male-like pattern and the presence of tails may be ancestral in the female, particularly in view of the fact that (i) the female pupa has tails in all races, including those in which the female butterfly has not got them, a very strong indication that this character is primitive, and (ii) the female of $P$. nobilis has a very similar appearance to its own male and the non-mimetic yellow males and females of $P$. dardanus. If we assume that the black and yellow tailed form is not primitive we must conclude that the similarity between the females 
of races meriones, humbloti and those of the species $P$. nobilis, as well as that of the yellow (male-like) ones in race antinorii, is due to convergence. The geographical disposition makes it more than unlikely that antinorii could have been established directly from race meriones or vice versa.

One might argue that in the case of these two races convergence in respect of yellow pigment is extremely probable since the presence of yellow pigment is controlled by a single allelomorph. However, it is not only with respect to the presence of tails and yellow pigment that the forms are similar. The details of the black pattern, which are multifactorially controlled, are also much alike in the females. A cross between meriones and antinorii might distinguish between convergence and common ancestry. If it were found that the same modifiers controlled the distribution of black in both races it would all but rule out convergence since the probability of using the same modifiers to evolve the male-like pattern in both races is negligible. Even in the absence of such data it seems reasonable to proceed on the assumption that $P$. dardanus was originally monomorphic, tailed and with a black and yellow appearance similar to that of the present-day males.

\section{THE ORIGIN OF MIMICRY IN ABYSSINIA}

The Abyssinian race of $P$. dardanus is, at the present day, well isolated from the other races. It is therefore of some interest to consider how the mimicry arose in this area. We can assume with a fair degree of certainty that the mimicry in Abyssinia is being maintained by selection since appropriate models are present and the tails of the females, particularly those of the mimics, although not absent, are reduced compared with those of males and Madagascan females, as the result of the presence of specific sex-controlled modifiers (Clarke and Sheppard, I96oc). Only three (possibly four) mimics are known from this population and, surprising as it may seem, the two mimics tested (hippocoonides and cenea) are both recessive to the non-mimetic yellow form. Clarke and Sheppard (1960c) have obtained evidence for believing that this recessiveness has been evolved owing to the disadvantageous appearance of the original intermediate heterozygote. Now if a mutant producing imperfect mimicry in the heterozygote arose in a monomorphic population one would expect selection for modifiers improving the resemblance to the model. In such circumstances the form is unlikely to become recessive, for to do this the appearance of the heterozygote would have to be disadvantageous which it could not be if it were being selected on its visual appearance, as in mimicry (Sheppard, 1958). Consequently if the original population of females were male-like, the mimics did not arise in Abyssinia by mutation and become established on account of selection for their visual effect, otherwise they would be dominant, not recessive. They 
must therefore have been introduced in large numbers by hybridisation. Only thus could the gene-frequency have bcen raised sufficiently for enough homozygotes to be produced to allow the gene to become established despite the disadvantageous appearance of the heterozygote. The only other reasonable hypothesis to account for the dominance relationships is that the original population was mimetic and that it was the yellow form which arose by mutation and increased in frequency, implying convergence between antinorii and meriones, an hypothesis which seems slightly the less likely of the two (see above).

The massive and prolonged hybridisation envisaged here could hardly have been all in one direction, so that for supporting data we can look at adjacent races for evidence of hybridisation. Now since the genitalia of antinorii males are of the East African type such race mixture as has occurred is likely to be with an castern race. Moreover, geographical considerations suggest that the most probable race is polytrophus from Kenya. An increase in rainfall would allow the forests of the Kenya and Abyssinian highlands to become contiguous by spreading into the dry areas between them, particularly in the vicinity of Lake Rudolf. In fact two areas of mountain-top forest in this intervening region do support, at this moment, populations of $P$. dardanus (of the eastern race) in which a very remarkable mimic ochracea has evolved, copying the local common Amauris echeria septentrionalis.

In polytrophus there are yellow females, proto-hippocoonides, which arc identical to our antinorii yellow/hippocoonides heterozygotes $\left(\mathrm{H}^{\mathrm{y}} h\right)$ of the second and subscquent backcross generations to Central African stock. Therc seems little doubt that proto-hippocoonides which is found nowhere else (except as a rare aberration in neighbouring races) is a yellow/ hippocoonides heterozygote and that its differences (the shade of the yellow and the distribution of black pigment) from the yellow Abyssinian females are due to the polytrophus gene-complex. If this interpretation of the genetics of proto-hippocoonides is correct it militates against the hypothesis of convergence, since there is no indication of this occurring in the polytrophus race, and helps to support that of hybridisation by accounting for the presence of yellow females in Kenya but nowhere else in continental Africa except Abyssinia. A polymorphism, however maintained, is likely to result in the heterozygotes becoming advantageous to both homozygotes (Ford, I940; Sheppard, I $953 a$ and see below). Consequently there is no difficulty in accounting for the persistence of the allelomorphs for yellow in Kenya where the effectiveness of the mimicry, and therefore counter selection against intermediate phenotypes (such as proto-hippocoonides), is much reduced owing to the scarcity of models (see Sheppard, 1960). Had the models been more abundant one might have expected protohippocoonides to have been eliminated.

There are other features of the polytrophus race which support the hybridisation hypothesis. (i) Not only are the forms in this race more 
variable than in any other, as might be anticipated after hybridisation in the absence of strong selection, but the variability is of the type to be expected. Thus there is a tendency for intermediates between otherwise distinct forms to appear, suggestive of a breakdown of dominance similar to that produced in our race-crosses. (ii) Even more convincing is the decided tendency in polytrophus for the black bar in area 2 (see fig. 2 in Clarke and Sheppard, I96oc) to be reduced or missing, and area 3 to be increased in size, a feature common to our antinorii hybrids (Clarke and Sheppard, ig6o $b$ and $c$ ). This similarity between forms of race polytrophus and the antinorii hybrids with Central African stock is particularly marked in bright- and pale-poultoni. (iii) In race polytrophus alone are found, on rare occasions, females with short tails. Such females are identical in appearance with tailed heterozygotes $(T t)$ in our backcross families of the Abyssinian and Madagascan tailed races $(t t)$ to Central African (TT) stock. The presence of these females in polytrophus suggests that the allelomorph $t$ is still present, albeit at a very low frequency. (iv) The males of the race have genitalia of the eastern races but reduced black markings which are so characteristic of antinorii and not of the other eastern forms.

The chief difficulty with the hypothesis would seem to be in explaining the absence of the tailless condition in Abyssinia today if the females of the Kenya populations were already tailless at the time of hybridisation. On the other hand one might maintain that the females were tailed at that time. This is altogether unsatisfactory since we would also have to assume that despite the weak selection for mimicry, as indicated by the presence of proto-hippocoonides and other imperfect mimics, it has been sufficiently strong to establish the allelomorph $T$ at high frequency even though its advantage lay only in the improved mimicry it afforded. However, the presence of the tailed condition in all antinorii females is consistent with hybridisation with a tailless Kenya race. The locus concerned is not linked with that controlling colour-pattern and consequently the two conditions will tend to be distributed at random in a population polymorphic for both. Now, even if there is strong selection for the absence of tails in mimetic Abyssinian females, a mild disadvantage of this condition in the yellow females would ensure the elimination of the allelomorph (particularly a semi-dominant one) since less than 20 per cent. of the females are mimetic. In Kenya the yellow females are rare (about 6 per cent., Ford, I936) and in consequence the reverse process would occur, although more slowly, owing to the mildness of the selection for mimicry and the semi-recessiveness of the tailed character. This would account for the continued presence of the gene $t$ at low frequency in race polytrophus. That there is, in fact, selection against tails in the mimics and for them in the yellow females is supported by the fact that the yellow Abyssinian females have longer tails than do the mimics. 


\section{THE ORIGINAL MIMIC}

It is as difficult to decide the pattern of the first mimic as it is to determine the primitive female colour-pattern. We have, however, some theoretical points to help us. It was pointed out by Sheppard (r958) that a gene which is selected because of its advantageous effect on the appearance of an animal is likely to become dominant if it and its allelomorph are retained in a population. Moreover, such an allelomorph initially has a better chance of establishing itself if it is not entirely recessive in its effect. For similar reasons a second mutant is likely to become dominant to the first. Consequently the first mimic to appear is likely to be recessive to all others but semi-dominant to the original form when in a gene-complex which has never experienced the mutant. It is of course possible that the second mutant arose before the first was very common, in which case the latter might become recessive to it. We can therefore only say that the bottom recessive mimic is likely to be the oldest or at least established while the non-mimetic form was still the commonest variety.

Now hippocoonides (and its modifications hippocoon in West Africa, and niavioides in Abyssinia), besides being the most widely distributed and frequently the commonest mimic, is also recessive to all other sympatric forms. It is therefore probable that it was the first of the extant mimics to evolve. Such a view becomes even more plausible when we consider that a widespread and common model such as $A$. niavius, whose presence exerts a powerful selective effect as judged by the high frequency of hippocoonides in many areas, has a better chance of evoking mimicry than one with a restricted range and therefore a selective influence on only a restricted proportion of the potentially mimetic species. The gene controlling hippocoonides also has the necessary attribute of semi-dominance to the presumed primitive yellow females of the monomorphic Madagascan race. The heterozygote in the $\mathrm{F}_{1}$ hybrid with Central African stock produces a good mimetic resemblance as far as the black pattern is concerned and is inferior to hippocoonides itself chiefly in the ground colour of the pale areas which is yellow (lighter than in meriones females), not white. Such a heterozygote might well possess some mimetic advantage where the form is rare and the model abundant.

Trimen (1870), when the genetics of $P$. dardanus was quite unknown, suggested, from a consideration of the pattern, that mimicry in this specics had been based on an extension of the black costal margin of the forewing. This black bar extends from the base along the costa ending near the extremity of the cell and has a tendency to curve backwards distally. An extension of this backward curve to the outer margin of the wing near the inner angle would divide the pale areas in a way characteristic of nearly all the mimetic patterns. Now the allelomorph controlling hippocoonides does just this in the heterozygote with the yellow allelomorph in the gene-complex of the Central 
African stock and Madagascan hybrids of the $F_{1}$ and first backcross generations to the South African race. Thus both the genetic and morphological data are in agreement in singling out hippocoonides or some modification of it as the original mimic.

\section{THE SUPER-GENE}

Both Mather (1955) and Sheppard (1953b) have pointed out that once a polymorphism is established there is likely to be a gradual incorporation of new mutants into the " switch mechanism" to produce a super-gene. To illustrate this process one can use the characters presence or absence of tails in mimetic species belonging to the genus Papilio. All the available models for $P$. dardanus are tailless since the distasteful Aristolochian swallowtails, which can serve as tailed models in other areas, are not found on the African continent. Consequently a mutant reducing or eliminating the tails will be at an advantage visually whenever most of the females are mimetic. However, as we have argued above, where the mimics are rare and the yellow females common such a character will be, on average, at a disadvantage since, although at a premium in the mimics, it is at a disadvantage in the commoner male-like (yellow) females. There will be, therefore, no balanced polymorphism, the tails being either present or absent depending on the frequency of the mimics and ultimately of the models. Had tailed models been abundant in Africa it is probable that the allelomorph $T$ for the absence of tails would never have established itself. In the South American swallowtail Papilio lysithous there are three mimics lysithous, pomponius and rurik present in both sexes and mimicking the Aristolochian swallowtails Atrophaneura nephalion, A. perrhebus and A. chamissonia respectively, the first two of these models being tailed and the last tailless. However, all the mimics have tails and in this follow the character of the majority of models. It seems fairly certain that a mutant eliminating the tails, had it occurred in the same chromosome as the allelomorph giving rurik, would have put insects possessing it at an advantage and a polymorphism with respect to the presence or absence of tails would have ensued. Moreover, since any crossover between the loci concerned, in the double heterozygote, would result in a disadvantageous arrangement of the pairs of allelomorphs there would be selection against it and the loci controlling colour-pattern and tails would become incorporated into a super-gene (Kimura, 1956; Mather, I955; Sheppard, I953b).

Just such a super-gene seems to be present in Papilio memnon. In this species there are two non-mimetic tailless forms of which the genetics are known, laomedon which is like the male, and isarcha, the latter being due to a sex-controlled gene dominant in effect. A second unlinked dominant converts isarcha, but not laomedon, into achates, a tailed mimic of the Aristolochian tailed swallowtail Atrophaneura coon. Other than the presence of two closely linked loci, controlling pattern and 
tails respectively, there secm to be only two possible explanations for the genetic situation in $P$. memnon: (i) the rather unlikely one that the mutant by chance controls both colour-pattern and wing shape or (ii) that there has been strong selection for sex-controlled modifiers which interact with achates but not laomedon or isarcha to producc tails, in the same way that modifiers reducing tail length in the mimics of $P$. dardanus, race antinorii, seem to be being selected at the present time. Whichever of these explanations is correct the principle seems clear that mutants which are advantagcous in the presence of one form but disadvantageous in that of its alternative are not likely to establish a polymorphism unlcss the two responsible loci are or become closely linked (Kimura, I956; Sheppard, I955). Thus oncc a polymorphism is established as the result of disruptive selection one must expect the gradual accumulation of other mutants on the controlling chromosome and the formation of a super-genc as Mather (1955) predicted.

The same principle should hold equally for the different elcments of a mimetic colour-pattern and we found on examining the various forms of $P$. dardanus that thcy arc made up of different combinations of a few simplc elements such as the distribution of black on the forewings and on the hindwings as well as variations in the ground colour of the pale areas of both wings. It therefore seems possible that the apparent multiple allclomorphic series controlling the colour-pattern in all forms investigated is really a supcr-gene in which various combinations of linked allelomorphs control each pattern. There is no direct evidence for this hypothesis from the breeding data since no crossover has been detected. If selcction for close linkage has been prolonged, crossing-over is likely to be almost as rare as mutation. There is somc indirect evidence for the presence of a super-gene. The form niobe is controlled by a single genetic unit and the form is dominant to hippocoonides. The same mimic is also produced by the heterozygotc between the factors for trophonius and planemoides both of which are sympatric with niobe. Now a crossover in this heterozygote could produce a combination which would givc niobe inherited as a single unit (the other crossover class being hippocoonides). Consequently a possible mechanism for producing a mimic by crossing-over exists and if the gene-complex had already been adjusted to the heterozygote the mimicry would be good from its first occurrence. Thc other evidence for a super-gene comes from race polytrophus, in which the models are rare and the mimicry poor. Now it is in just this race, and this race alone, that mimics with yellow fluorescent pigment are found and it is herc also that the allclomorph producing the yellow of antinorii is also found (proto-hippocoonides). These mimics with this yellow pigment are not heterozygous for proto-hippocoonides. It therefore seems not unrcasonable to suppose that these imperfect mimics in which the white areas are replaced by yellow male pigment, result from crossing over within the super-gene between parts controlling the mimetic pattern and that determining the presence of yellow, and 
that these products have not been eliminated because of the scarcity of the models. It is perhaps of importance to note that one of these imperfect mimics, proto-trophonius (apparently controlled by an allelomorph of planemoides, Clarke and Sheppard, Ig6oa) is an exact replica in colour-pattern of a heterozygote between trophonius and the yellow Madagascan form which behaves as an allelomorph of it.

The hypothesis put forward by Mather (1955) that disruptive selection could lead to the establishment of a polymorphism controlled by a super-gene is in full agreement with the data from $P$. dardanus as well as with the artificial selection experiments of Thoday (1959). Moreover, the data further suggest that when there are a large number of optimum phenotypes which differ by combinations of a limited number of characters there are likely to evolve a number of allelomorphs of the super-gene as the result of selection for some but not all of the crossover classes within the super-gene. Thus it is not impossible that hippocoonides itself was not the first mimetic pattern but that the first element was one giving an extension of the black costal border of the female and that later a second mutant which replaced the yellow pigment by white was incorporated. Subsequently other mimetic patterns could have been evolved as new mutants giving non-fluorescent yellow or orange-brown pigment arose and still others modified the distribution of black pigment.

The presence of a super-gene not only explains the apparent participation of only one locus in the control of the colour-patterns but also reduces the difficulty felt by many people of imagining the evolution of a gene-complex which is adjusted to many allelomorphs in one area. If the pattern is controlled by combinations of relatively few linked mutants the gene-complex only has to be adjusted to each factor individually for them to produce the optimum effect in all their many combinations. Such an adjustment would explain why the black bar in area 2 of the antinorii $\mathrm{F}_{\mathbf{1}}$ hybrids is absent or much reduced, not only in cenea/yellow and hippocoonides/yellow heterozygotes in which the dominance of yellow has been evolved in antinorii (Clarke and Sheppard, I $960 c$ ), but also in heterozygotes using the allopatric forms trophonius, natalica, bright-poultoni, pale-poultoni and leighi.

A marked feature of mimicry in $P$. dardanus, the persistence of many different non-mimetic forms which are unlike the males, is also explained by the super-gene hypothesis. The various linked allelomorphs are certain to have other effects than those on colour, some of which will be advantageous and others disadvantageous (see Caspari, I950). Now the advantageous effects will become dominant and the disadvantageous ones recessive; we already have evidence that they do so in the case of colour-pattern. Consequently on average the heterozygotes will come to be at an advantage to the homozygotes (Sheppard, I 953a) and the polymorphism is likely to persist even in the absence of models. Moreover, crossovers will sometimes incorporate these advantages of the heterozygote sufficiently markedly for them to persist 
even if the resulting pattern is not mimetic (for example leighi or natalica). The chance of persistence will be particularly great where the selection for mimicry is most relaxed, as in polytrophus. Now it is in just this race that the imperfect mimics and non-mimetic forms are particularly well represented.

\section{SUMMARY}

None of the evidence is conclusive on its own but there seems little doubt, when all of it is considered together, that:

I. The pre-mimetic pattern of the female was similar to that of the male of the present time.

2. The presence of mimics in race antinorii (from Abyssinia), although maintained by selection, was originally due to hybridisation with race polytrophus from Kenya and not to mutation within the race.

3. The original mimetic pattern resulted from a mutant causing an extension of the black pigment of the female's costal border towards the inner angle of the forewing.

4. Other loci have become incorporated in the chromosome pair carrying the original mutant and have formed a super-gene which now exists in various forms as the result of recombination and selection.

5. The persistence of the polymorphism over a long period has resulted in the evolution of a selective superiority of some heterozygotes.

Acknowledgments.-We are very grateful to Dr E. B. Ford, F.R.s., for his encouragement and for reading the manuscript in detail. We are also indebted to Dr A. B. Acton, Dr A. J. Cain, Dr G. A. Harrison, Professor K. Mather, c.ß.E., F.R.s., and Professor R. J. Pumphrey, F.R.s., for their helpful comments. Our thanks are also due to the Nuffield Foundation without whose support most of the genetic work on $P$. dardanus could not have been undertaken.

\section{REFERENCES}

CASPARI, E. 1950. On the sclective value of alleles $R t$ and $r t$ in Ephestia kühniella. Amer. Nat., 84, 367-380.

Clarke, C. A., AND ShePpard, P. M. I96oa. The genctics of Papilio dardanus Brown. Pt. I, II and III Genetics (in press).

Clarke, C. A., AND Sheppard, P. M. 1960 $b$. Evolution of mimicry in the butterfly Papilio dardanus Brown. Heredity 14, I63-1 73 .

ClARKE, C. A., AND SHEPPARD, P. M. Ig6oc. The evolution of dominance under disruptive selection. Heredity ${ }_{4} 4,73-87$.

FORD, E. B. 1936. The genetics of Papilio dardanus Brown (Lep.). Trans. Roy. Ent. Soc. Lond., 85, 435-466.

Ford, E. B. 1940. Polymorphism and taxonomy. In The New Systematics, ed. Huxley, Oxford Univ. Press, London.

FORD, E. B. 1953. The genetics of polymorphism in the Lepidoptera. Advanc. Genet., 5, 43-87.

KIMURA, M. 1956. A model of a genetic system which leads to closer linkage by natural selection. Evolution, $10,278-287$.

MATHER, K. 1955. Polymorphism as an outcome of disruptive selection. Evolution, $9,52-6 \mathrm{I}$. 
ShEPPARD, P. M. 1953a. Polymorphism and population studies. Evolution Soc. Exp. Biol. Symp., 7, 274-289.

Sheppard, P. м. I $953^{b}$. Polymorphism, linkage and the blood groups. Amer. Nat., 87, 238-294.

SHEPPARD, P. M. I955. Genetic variability and polymorphism, a synthesis. Cold Spring Harbor. Symp. Quant. Biol., 20, 271-275.

ShePpard, P. м. 1958. Natural Selection and Heredity. Hutchinson, London.

SHEPPARD, P. M. 1960. The evolution of mimicry; a problem in ecology and genetics. Cold Spring Harbor. Symp. Quant. Biol., 24, I31-140.

THODAy, J. м. 1959. Effects of disruptive selection. Proc. 15th Int. Cong. Zool., pp. I 27-1 30.

TRIMEN, R. 1870 . On some remarkable mimetic analogies among African butterflies.

Trans. Linn. Soc. Lond., 26, 497-522. 